\section{NAC̣ÃO, MEMÓRIA E HIST́ÓRIA NA ÁFrICA DO SUl ATRAVÉs DE JOHN DUBE}

Nation, Memory and History in South Africa through John Dube

\section{RESUMO}

John Dube (1871-1946) consiste numa figura central da história e memória sul-africana contemporânea. Há pelo menos duas tendências significativas entre aqueles que, entre final do século XIX e início do século XXI, o têm tomado como sujeito e objeto de interesse. De um lado, numa perspectiva dominante nos tempos do Apartheid (1948-1994), há aqueles que identificam Dube como colaborador da implementação desse regime segregacionista. De outro lado, a exemplo do que ocorre no contexto de construção da Nação Arco-Íris, há aqueles que o vêem como personagem central, como um herói das lutas contra a segregação racial. Uma profusão de dispositivos tem sido empregada para produzir, atualizar ou questionar o legado de Dube: sua existência assume uma dimensão pública, sendo objeto de diferentes estratégias e tramas de competição política e batalhas pela memória da nação sul-africana.

Palavras-chave: John Dube (1871-1946), Nação, Memória, História, África do Sul.
Antonio Evaldo Almeida

\section{BARROS}

\section{(D) antonioevaldoab@gmail.com}

Universidade Federal do Maranhão Universidade Estadual do Maranhão São Luís, MA, Brasil

\section{ABSTRACT}

John Dube (1871-1946) is a central figure in modern South African memory and history. There are at least two significant trends among those in which, between the end of the 19th century and the beginning of the 21st century, Dube was the object or subject of interest. Thus, on one hand, in a dominant perspective during Apartheid (1948-1994), there are those who tend to identify Dube as a collaborator in the implementation of that segregationist regime. On the other hand, especially in the context of building the Rainbow Nation, there are those who see Mafukuzela as a central figure, a hero in the historical struggle against racial segregation. A profusion of devices has been used to produce, update, or question the Dube legacy: his existence assumes a public dimension, being the object of different strategies and plots of political competition and battles for the memory of the South African nation.

Keywords: John Dube (1871-1946), Nation, Memory, History, South Africa. 
Iguns historiadores e cientistas sociais, sobretudo a partir de início dos anos 1980, sentiram-se motivados a investigar acerca dos meios pelos quais as nações conseguiram se tornar uma referência fundamental para a constituição de sentimentos de pertença. Embora reconhecendo se tratar de um tema sobre o qual há pouco consenso analítico, esses estudos evidenciaram que o fenômeno da nação, longe de caracterizar algo natural, atávico e imemorial, é uma criação recente, um artefato sociocultural que se configura como entidade histórica no contexto moderno e contemporâneo (ANDERSON, 1983; BALAKRISHNAN, 2000). Observaram também que a nação e o vínculo desse artefato com seus fenômenos associados, a exemplo do nacionalismo, do Estado nacional, dos símbolos nacionais e das interpretações e memórias históricas, podem ser tratados similarmente a liberalismo ou fascismo, bem como a parentesco e religião, em termos antropológicos - com efeito, tem sido recorrente a definição da nação como uma "comunidade política imaginada" (ANDERSON, 1983). Notaram ainda que esses fenômenos são centrais para o estudo das tradições inventadas no mundo moderno e contemporâneo (HOBSBAWM, 1997, p. 22), pois, dentre outras possibilidades analíticas, consistem em ocasião privilegiada para se observar um duplo e correlato movimento: a invenção de tradições, de um lado, de comando, controle e domínio e, de outro lado, de subserviência e subordinação (RANGER, 1997). Além disso, sugeriram que um estudo sobre nação deveria examinar, em primeiro lugar, as tensões e lutas sociais e os processos de (in)visibilização social - comumente articulados a operadores sociais como etnia, raça, gênero e classe - em meio aos quais o artefato nacional se torna uma expressão significativa (VERDERY, 2000, p. 243). ${ }^{1}$

A ênfase em algumas dimensões da tessitura da África do Sul enquanto nação, destacando-se suas correlações com interpretações e memórias históricas, no contexto contemporâneo, é o foco deste estudo. As evidências analisadas, certamente, permitem interpretar a nação como um fenômeno construído em meio a dissensos, ambiguidades e conflitos e cujas teias constitutivas consistem, antes de tudo, nas lutas que se travam tanto no curso do processo histórico quanto na revivescência ou esquecimento de determinadas memórias sobre essa história, o que, envolve, irremediavelmente, os produtores dessa memória e história, os diferentes sujeitos e grupos sociais que ocupam, desigualmente, um dado território nacional.

Esta pesquisa parte do entendimento de que "enquanto a África permanecer desconhecida dos brasileiros, tanto à direita, quanto à esquerda, tanto os reacionários racistas, travestidos de liberais, quanto os que labutam arduamente para sua extinção, vão continuar prisioneiros de uma visão da África que foi criada para dominar" (ZAMPARONI, 2007, p. 49). Além disso, inspira-se, teórica e politicamente, no reconhecimento de que os estudos realizados sobre e/ou a partir do continente africano têm levado a transformações no campo das ciências sociais e humanas (BATES; MUDIMBE; O'BARR, 1993) e de que pesquisas realizadas no eixo Sul-Sul poderiam se estruturar em termos de democratização epistemológica (SANTOS; MENESES, 2009). Nesta perspectiva, “o que se busca é um prisma localizacional: uma visão que lê o saber-poder não hierárquica, mas heterarquicamente" (BARROS, 2018a, p. 43), destacando-se que constitui fonte de teoria e explicação dos eventos sociais e 
históricos não apenas o Norte Global, como também o Sul Global, cuja relevância reside em sua "ex-centricity: in the angle of vision it provides us from which to estrange our world in order better to make sense of its present and future" (COMAROFF, Jean; COMAROFF, Joan, 2012, p. 126-127).

A intenção original deste estudo consistia, especificamente, em acompanhar de perto a prosa de John Langalibalele Mafukuzela Dube (1871-1946), fundador do African National Congress (ANC), tentando concatenar algumas de suas posições e observar de que maneira suas intervenções poderiam estar relacionadas a outros homens e mulheres, especialmente negros, de sua época, em África e fora dela. Dube costuma ser apresentado como um dos principais agentes difusores do educacionismo negro na África Colonial, ideia segundo a qual, para o desenvolvimento dos africanos, seria fundamental a conciliação entre educação e trabalho, sobretudo de caráter técnico (VALDÉS, 2008, p. 70-71). De fato, naqueles tempos de intensa exploração colonial, Dube estava preocupado, sobretudo, com questões de caráter prático. Já em 1891, em seu $A$ familiar talk upon my native land, Langalibalele destacava a necessidade de desenvolvimento agrícola e industrial do povo zulu (DUBE, 1891).

Durante realização de pesquisa de campo e arquivística, a partir de 2009, na região de Kwazulu-Natal, África do Sul, foi possível identificar diversos documentos, de caráter científico, hagiográfico ou laudatório, produzidos, por e sobre John Dube, entre final do século XIX e 2012, ano do centenário do ANC, e disponíveis, particularmente, nos arquivos da Killie Campbell Africana Library (KCAL), em Durban, e no Alan Paton Centre (APC), em Pietermaritzburg. A identifição desses documentos nesses "lugares de memória" (NORA, 1993) se revelaria parte integrante do próprio objeto desta pesquisa. De fato, pelo menos desde 1922, o sistema de arquivos da África do Sul se encontrava sob domínio do State Archives Service (SAS), que absorvera a cultura burocrática e a ideologia do Apartheid (1948-1994), havendo uma política de coleta que dirigia, deliberadamente, os arquivistas para longe dos diferentes grupos sociais que constituíam a base da sociedade, evitando, por exemplo, a documentação da oralidade (HARRIS, 2002, p. 72-74). ${ }^{2}$ Esta realidade começaria a mudar a partir dos anos 1970, quando a história social e as perspectivas históricas revisionistas passaram a influenciar o programa do SAS, surgindo, então, algumas instituições dedicadas a dar voz aos sem voz através de acervos arquivísticos. Alguns desses arquivos resultariam de coleções privadas, a exemplo da KCAL, cujas obras (livros e documentos diversos) pertenciam à colecionadora Sra. Margareth Roach Killie Campbell (1881-1965), e do APC, oriundo do acervo do romancista e membro-fundador do Liberal Party of South Africa (1953-1968), Alan Paton (1903-1988), que era contrário à segregação racial. Em 1988, a viúva de Alan Paton, a Sra. Anne Paton, doou a coleção, um repositório de documentos sobre organizações e indivíduos que estiveram envolvidos na luta contra o segregacionismo, para a Universidade de Natal. Certamente, a própria história dessas instituições ilustra a articulação entre as experiências de reconstrução da memória e as tentativas de redefinição da nação na África do Sul, um processo quase sempre dominado pelo drama da passagem, comumente anunciada como inconclusa, de uma África do Sul oficialmente segregada para uma comunidade nacional imaginada e edificada como democrática e antirracista. 
A presença desses arquivos se torna ainda mais relevante quando se considera que, entre 1990 e 1994, grandes volumes de registros públicos foram destruídos em uma tentativa de se manterem escondidos os segredos mais sombrios do estado do Apartheid. Essa destruição seletiva não abraçou apenas os registros públicos, mas também aqueles de caráter privado, como os acervos de indivíduos e organizações confiscados pela polícia e destruídos antes das eleições gerais de 1994. Outros processos de apagamento de memória também teriam sido amplamente utilizados pelo estado do Apartheid, com milhares de vozes de oposição sendo eliminadas através de meios como assédio informal, censura da mídia, várias formas de proibição, detenção sem julgamento, prisão e assassinato. Esses casos vieram à tona entre 1996 e 1998, no âmbito de uma investigação, realizada pela Truth and Reconciliation Commission (TRC) sobre a destruição de documentos públicos, que concluiu ter havido, com a participação de membros do alto escalão do governo e do Estado, a destruição oficial, sistemática e seletiva de alguns registros. (HARRIS, 2002) No início dos anos 2000, como membro daquela comissão de investigação, o arquivista Verne Harris (2002, p. 65) assim se posicionava: "If, as many archivists are wont to argue, the repositories of archives are the world's central memory institutions, then we are in deep, amnesic trouble".

Enquanto analisava esse material arquivístico, bem como as narrativas variadas sobre Dube disseminadas na rede mundial de computadores, formava minhas próprias impressões sobre a África do Sul, cuja experiência histórica, ao lado daquela dos Estados Unidos, muitas vezes serviu, para, em perspectiva comparada, pensar as relações raciais no Brasil. ${ }^{3}$ O fato é que cada vez mais refletia sobre as relações raciais na África do Sul, especialmente, as tentativas de construir a Raibown Nation, o que deveria criar possibilidades para a eclosão e consolidação de experiências de sociabilidade inter-raciais, movimento que era acompanhado pela persistente separação dos grupos raciais no cotidiano da população - uma espécie de herança perene dos tempos do Apartheid.

Assim, o trabalho parecia estar seguindo dois caminhos investigativos diferentes: de um lado, descrever e analisar o pensamento de um sujeito que viveu entre o último terço do século XIX e a primeira metade do século XX, momento de instituição das principais leis segregacionistas que marcariam o Apartheid (BARBOSA, 2015; CELL, 1982; POSEL, 1991); de outro, acompanhar processos mais contemporâneos de construção de uma nova imaginação nacional sul-africana. Foi então que, depois de uma análise prévia da documentação produzida sobre Dube, tornou-se possível levantar a hipótese de que as mudanças e diferenças nas formas de interpretar a vida e obra de Mafukuzela, relacionavam-se, umbilicalmente, ao modo como os intérpretes e interessados em Dube concebiam a própria história da África do Sul. Desse modo, aquilo que, inicialmente, parecia levar a dois lugares distintos, foi se configurando como o avesso e o direito de um mesmo processo, cujo essencial é, aqui, apresentado. 


\section{Descobrindo as faces de John Dube}

John Dube nasceu em Natal, na África do Sul. Seus pais, Elizabeth Dube e James Dube, converteram-se ao cristianismo na American Zulu Mission (AZM), que se estabelecera em Kwazulu-Natal entre 1835 e 1895 e por meio da qual o pai de Dube se tornaria um dos primeiros africanos da região a ser ordenado pastor. Os missionários e os africanos convertidos acreditavam na necessidade do progresso do continente africano, o que, para eles, dependeria da articulação entre formação técnico-educacional e propagação do cristianismo. De um lado, as ações desses sujeitos se consolidariam em meio a dissensos e enfrentamentos, particularmente, quando se atenta para os valores e as práticas costumeiras comuns aos diferentes povos africanos. De outro lado, acabariam levando à consolidação de setores africanos cristianizados e educados em padrões ocidentais. (DINNERSTEIN, 1976; KUMALO, 2011; 2013)

Dube viveu e foi educado em instituições ligadas a AZM. Em 1887, ele viajou para os EUA com o missionário norte-americano W. C. Wilcox (1850-1928), que permaneceu por mais de 40 anos na África do Sul (KUMALO, 2013). Dube teve passagem pelo Oberlin College cuja filosofia integrava ideais de educação e trabalho e que, em 1835, havia se tornado a primeira instituição norte-americana de ensino superior a admitir estudantes negros e do sexo feminino. Dube retornara aos EUA outras vezes, em busca de formação educacional e tentando angariar fundos para a construção e manutenção de uma escola industrial similar ao Tuskegee Negro Normal Institute que, em 1888, foi fundado com o lema trabalho e educação, tendo como primeiro diretor o afro-americano B. T. Washington (1856-1915). Em 1901, Dube adquiriu 200 acres de terra no distrito de Inanda, em Natal, onde construíra sua escola, que também funcionava como igreja, o Instituto Ohlange. Em 1903, Dube foi um dos fundadores do primeiro jornal zulu-inglês, llanga lase Natal (O Sol de Natal), que Ihe ajudou a estabelecer seu reconhecimento público.

Em 1909, Langalibalele participou das reuniões dos africanos contrários ao Act of Union que, dentre outras determinações, criava as condições legais para a instituição oficial de práticas segregacionistas, que acabaram se consolidando, oficialmente, anos depois, com o Apartheid. Em 1912, Dube se tornara o primeiro presidente do South African Native Congress que, posteriormente, se definiria como ANC, ao qual, ao longo do século XX, a maioria dos principais líderes sul-africanos - como Nelson Mandela - estaria vinculada. Dube se opusera ao Native Land Act de 1913, que destinava $87 \%$ das terras sul-africanas para os brancos, acompanhando uma delegação de africanos que, em 1914, dirigiu-se a Londres para protestar contra essa lei. Em 1917, ele foi deposto - ou deixara - a presidência do ANC num contexto de tensão e divergências de opinião dentro do Congresso sobre os princípios e implicações práticas da segregação. Nos anos 1930 e 1940, Dube participaria, esporadicamente, de ações no âmbito do ANC.

Dube parece ter tido papel relevante nas negociações das chamadas "native bills", de James Hertzog (1866-1942), projeto de leis cuja discussão foi iniciada no parlamento em 1931 e tinha a intenção de permitir que os negros se desenvolvessem 
ao seu modo e em suas áreas, sendo aprovado em 1935, ao mesmo tempo em que ocorria o progressivo processo de remoção de africanos negros de seus territórios originais. Também nesse ano, Dube se tornaria, embora por um curto período, membro da All-African Convention, que unia africanos negros de diferentes tendências políticas e cujo objetivo era promover os direitos dos africanos através de boicotes e outros mecanismos. De 1936 até sua morte, em 1946, quando foi substituído por C. A. Luthuli (1898-1967), Dube representou Natal no Native Representative Council.

Essa apresentação sumária do itinerário de John Dube permite vislumbrar como ele se tornou uma figura central da história e memória sul-africana moderna. A começar pelo fato de que, embora submetido a diferentes versões e perspectivas, o interesse pela sua história é inseparável do conjunto de papeis e cargos por ele exercidos e das sucessivas tomadas de posição que adotou no espaço público. Porém, se essas realizações são bem conhecidas por aqueles que têm se interessado por sua vida e obra, é também significativo observar que os discursos e práticas atribuídos a Dube não costumam ser trazidos à tona de modo despropositado - a eles são destinadas ênfases e interpretações de natureza política, acadêmica ou artística, situadas no contexto social e histórico de seus produtores, numa cadeia de interpretações que envolve, além do próprio Dube, homens e mulheres que com ele conviveram ou que, posteriormente, o tomaram como objeto de suas narrativas.

A partir da análise do conjunto de práticas e representações instituintes de John Dube, é possível observar, em primeiro lugar, a existência de pelo menos duas tendências significativas entre aqueles que, ao longo do tempo, o têm tomado como objeto ou sujeito de interesse. De um lado, há aqueles que o identificam como colaborador direto ou indireto do processo de implementação do regime segregacionista sul-africano, tendência que não é exclusiva, mas se torna dominante nos anos do Apartheid. Aqui, Dube é visto como fantoche dos brancos, incentivador da solidariedade racial e, por conseguinte, promotor do apartheid, um exemplo de como ser fraco e ambíguo diante das forças sociais e da luta contra a opressão social e racial na história da Africa do Sul.

De outro lado, há aqueles que posicionam John Dube como personagem central das lutas históricas contra a segregação racial, inscrevendo-o como uma espécie de herói sul-africano. É possível observar focos desta tendência em diferentes contextos, como nas representações sobre Dube produzidas, nos anos 1970, no âmbito dos izibongos que lhe foram dedicados. ${ }^{4}$ Mas este padrão interpretativo se tornaria dominante no contexto de invenção da África do Sul como Rainbow Nation. Aqui, Dube é reabilitado como sujeito absolutamente envolvido nas lutas pela liberdade, opositor inteligente e perspicaz de ações e movimentos que visavam instituir o Apartheid e cuja obra e vida seriam exemplos de que, nas origens da nação sul-africana moderna, haveria projetos promissores de relações raciais não conflitivas, mas complementares, entre brancos e negros, afinal, como argumentara certa vez Mafukuzela, "without any doubt, the greater the distance between the white man and the black, the greater the loss to each" (DUBE, 1914). 
Em segundo lugar, é relevante destacar que as intervenções teóricas e práticas de e sobre John Dube tanto se alicerçam quanto fomentam determinadas concepções de história e desenvolvimento, comumente definidoras de certas ideias de nação. Nessa perspectiva, destacam-se, a depender do contexto e das intenções dos sujeitos e grupos sociais, tanto concepções progressistas e universalistas de desenvolvimento social e histórico quanto noções fundadas em ideias de diversidade e diferença.

\section{Dube em seu próprio tempo: entre a obliteração de ideias de integração racial e a edificação da segregação}

A África do Sul na qual nascera e vivera John Dube era similar a outros territórios africanos, uma vez que marcada pela implementação e reação à colonização europeia, intensificada a partir dos anos 1870. Consideradas solução para os problemas, especialmente aqueles econômicos, das metrópoles, as colônias também deveriam ser financeiramente autônomas. O setor privado metropolitano se apossava do essencial da atividade produtiva, terras eram confiscadas e impostos e formas compulsórias de trabalho instituídos. Marcado pela violência, esse empreendimento colonial interrompe o dinamismo histórico das sociedades africanas. A dominação, contudo, circunscreve-se, particularmente, aos espaços econômicos produtivos. Os movimentos de resistência são intensos e variados. (HERNANDEZ, 1999; ZAMPARONI, 1998) O poder das tradições cognitivas e morais dos africanos persiste e o Estado nem sempre tem sucesso em adentrar em espaços como a vida familiar, as áreas rurais e as estruturas de poder tradicionais (APPIAH, 1997).

"Expressão geográfica sem significado político que designava um território dividido em colônias britânicas, repúblicas bôeres e Estados africanos”, a África do Sul, nos anos 1850-1880, consistia numa região de povos em conflito (BHEBE, 2010, p. 169-170). Entre 1880 e 1930, período que engloba os anos de intensa atuação de Langalibalele, o expansionismo colonial, a cristianização e o ensino dos missionários e as revoltas, especialmente dos zulus, dariam conteúdo e forma a essa região (CHANAIWA, 2010; MARKS, 1970).

Dube, nesse contexto, não passava despercebido, nem entre negros nem entre brancos. Em 1891, três anos depois de chegar aos Estados Unidos, Dube publica $A$ familiar talk upon my native land, que resultara, principalmente, de suas palestras realizadas em igrejas e escolas norte-americanas. O livro foi selecionado por W. E. B. du Bois (1863-1963) e exposto na Exhibit of American Negroes em 1900, em Paris. Em A familiar talk..., Dube "parece operar entre a consciência de sua diferença e alteridade e o reconhecimento de padrões tidos como universais” (BARROS, 2012, p. 166). Nessa perspectiva, observa-se, de um lado, "a legitimação da ideia de civilização e de progresso (identificados com certa herança europeia e branca), antagônica ao que se toma como barbárie, primitivismo, atraso e desrazão, relacionada a certas práticas africanas e negras". De outro lado, "o reconhecimento de algumas diferenças históricas e culturais, uma pitada de relativismo cultural, numa perspectiva em que certas práticas comuns aos africanos são tidas como legítimas". Assim, “John Dube parece encontrar razoabilidade e normalidade onde o discurso dominante da civilização 
- através da cristianização e da educação ocidental formal, defendido e promovido pelo próprio Dube - encontraria só irracionalidade e despropósito. Esta parece ser uma característica central desta obra, bem como de outros escritos futuros de Dube". (BARROS, 2012, p. 167)

Já nas cartas de recomendação a $A$ familiar talk..., detalhes da personalidade, do comportamento e da visão de mundo do jovem John Dube são destacados pelos observadores missionários norte-americanos. Ele "is a bright, intelligent, and above all, Christian boy" em busca de "education which will fit him for the regeneration of his people in the dark continent": assim o descrevera o norte-americano, especialista em língua grega e latina, W. B. Crittenden (1891, p. 34, grifos do autor), ao recomendar a leitura de A familiar talk. F. H. Foster (1891, p. 35), professor de História da Igreja, lembrava que Dube estava nos Estados Unidos "for the purpose of securing an education with the intention of returning and devoting himself to work for his people". $O$ missionário David Rood (1891, p. 35), que esteve na Missão Zulu em Natal por quarenta anos, tendo convivido com a família de Dube, vê Langalibalele como "a coloured young man", "a Zulu from Natal, South Africa”, que nascera e vivera na estação missionária de Inanda e que estaria nos Estados Unidos em busca de aprimoramento educacional. Manifestadas por Crittenden, Foster e Rood, essas opiniões sobre Dube, um africano zulu, e sobre África, são, ao mesmo tempo, produto e meio de disseminação da ideia dominante no período, segundo a qual, o continente africano deveria ser regenerado através da cristianização e pelos próprios negros, como defenderiam o crioulo e padre católico senegalês, D. Boilat (1814-1901) e o ministro da Igreja Episcopal, o afro-americano A. Crummell (1891-1898), autor dos textos que inaugurariam o discurso pan-africanista (APPIAH, 1997). Além disso, essas representações sobre África e africanos podem ser entendidas como itens da biblioteca colonial, noção através da qual se entende que o gerenciamento da África colonial se sustenta num conjunto de saberes limítrofe e em tensão com as ciências sociais, um fenômeno transatlântico (MUDIMBE, 1988; 1994).

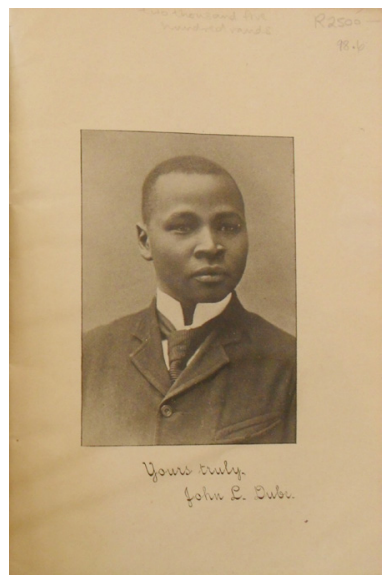

Figura 1. John Dube, no frontispício de A Familiar Talk...

Fonte: Dube (1891) 
Dube também despertara atenção de autoridades brancas de Natal. Em 1906, o governador da região o descrevia como "a pronounced Ethiopian who ought to be watched". Dois anos depois, F. R. Moor (1853-1927), tido como um homem branco raro, já que teria alguma simpatia pelos africanos, via Dube como "an entirely... exceptional character". Em 1912, J. X. Merriman, último primeiro ministro da Colônia do Cabo antes da formação da União da África do Sul em 1910, encontrou com Dube e o descreveu como "a typical Zulu, with a powerful cruel face. Very moderate and civilized, spoke extraordinarily good English..." Comentou ainda que "Dube in conversation gave me a glimpse of national feeling which reminded me of Gokhale [líder do Movimento de Independência Indiana contra o Império Britânico]. How they must hate us - not without cause". (MARKS, 1975, p. 164; 170)

Em 1927, W. C. Wilcox escrevera um breve artigo cujas ideias centrais seriam seguidas em apropriações futuras da vida e obra de Dube. Em tom biográfico, The story of John Dube é seguido do subtítulo The Booker Washington of South Africa.

Wilcox (1927) heroifica Dube: como um herói clássico (Kothe, 1987), a necessidade de aprendizado leva o futuro herói a se afastar de seu torrão natal. Ele, então, viaja para os EUA, onde estuda e se sustenta com o próprio trabalho, enfrenta dificuldades, mas as supera. "How he did for himself is a story of a heroic struggle against 'outrageous fortune', working on the road till he got sick, then in a printing office, and a barber's shop, and as porter in a Pullman [rede de trens que desde meados do século XVIII conduziam trabalhadores, sobretudo durante a noite, entre as cidades americanas]". Assim, no percurso, Dube adquire comedimento, capacidade de perdoar, humildade e astúcia, as competências essencias para a obtenção de sua heroicidade.

A heroificição de Dube produzida por Wilcox (1927) é acompanhada de outra ideiaforça que definiria futuros olhares e interpretações sobre Mafukuzela, mas, desta vez, nos complexos e tensos descaminhos do que seria identificado como marca central de sua vida e obra, a ambiguidade. Conta Wilcox que, certa vez, houve o início de uma revolta entre os estudantes, com potencial de interromper o trabalho missionário. Wilcox destaca que decidiu conversar individualmente com todos os envolvidos na situação, que nomeia, embora não caracterize mais detalhadamente, como "a rebellion and a fight" que teve lugar no playground da escola missionária. O fato é que alguns dos jovens apareceram para conversar com o missionário norte-americano, entre eles, "one of the principals in the fight [...] It was John Dube, a chubby boy of sixteen." Após um diálogo, que incluiu a leitura de uma passagem bíblica, Wilcox pedira a Dube que se reconciliasse com o colega com o qual brigara: "I couldn't have asked a harder thing of a scion of the fighting Zulu race. But he finally consented and went out. In a few minute he returned with sunlight on his face and said, 'It's all right now'." Wilcox não tem dúvidas de que "that was the beginning of a new life to one who has done more for the uplift of the Bantu race than any one native of the present generation". A relação de Dube com o cristianismo, marcada pela aceitação dos valores ocidentais, e sua tentativa permanente de conciliação e diálogo com os brancos seriam objeto de perspectivas severamente críticas, que tendem a desconsiderar a defesa contínua que Dube fizera dos africanos negros, especialmente, dos zulus. 
Dube, ainda em vida, receberia algumas das mais significativas honrarias possíveis para um homem negro na África do Sul de seu tempo, a exemplo do título honorário de Doutor conferido a ele, em 1936, pela Universidade da África do Sul, o que foi amplamente noticiado pelos principais jornais de circulação do período, a exemplo de The Mercury, que o inscreve como um "native leader", "a forceful public speaker in both Zulu and English" que "has written much on Native subjects" e "for many years has taken a prominent part in all matters affecting Native welfare and is regarded with respect by both Europeans and Natives" (UNIVERSITY..., 1936a). A primeira honraria do tipo destinada a um zulu também foi noticiada em The Natal Advertiser, periódico controlado pelo grupo de imprensa Argus, que "established a conservative approach to matter of political reporting, especially where racial issues were involved". Quando ideias socialistas se tornaram conhecidas na África do Sul depois da Primeira Guerra Mundial e nos anos 1920-1930, "the Argus Group became involved with a venture known as the Bantu Press, formed in 1931 to channel native thoughts away from politics and into safer pursuits" (BOURGAULT, 1995, p. 160). Dube, que teria dito que "it is not only an honour to myself, but to the whole 'Zulu nation', é visto como um "zulu educationist", o "founder and principal of Ohlange Institut", aquele que "work for natives", fundador do maior jornal nativo de Natal, "a pioneer in native education in South Africa" e "first president of the Bantu National Congress" (UNIVERSITY..., 1936b).

Quando da morte de Mafukuzela, em fevereiro de 1946, dois importantes tributos foram publicados, em sua homenagem, em Ilanga lase Natal. O também pastor Gideon M. Sivetye (1946), que convivera com Dube, rememora-o como "a great man, a patriot, a lover of his people". Sivetye, que pretende apresentar "facets of his life, upon which we can only touch here", mas que são "subjects fit for a biographer", acaba, de fato, prenunciando argumentos e visões que se tornariam emblemáticos e corriqueiros entre aqueles que, no futuro, se interessariam por Langalibalele: "well-educated, he was able to understand, interpret and mediate between Black and White, between tribal and 'educated' Africans; travelled, he was able to make comparisons and bring a ripe experience to bear upon his work"; além disso, "his work as a politician and public man caused him endless trouble - opposition, disappointment, mudslinging, clashes with police, etc."; finalmente, Dube é "a son of a chief, he knew the tribal people intimately, and instead of standing aloof from, he found opportunity, inspiration and strength in them; a son of a predikant, he was deeply religious and found refuge in God in times of stress and bitterness [...]" (SIVETYE, 1946). Esta interpretação, em particular, se tornaria central para a mais completa biografia sobre Dube, cujas bases são lançadas em 2001 e é publicada em 2011, pela historiadora H. Hughes: Langalibalele é, antes de tudo, parte de uma dupla elite, pois seria, ao mesmo tempo, representante de uma linhagem real zulu, os Qadi, ${ }^{5}$ e o porta-voz dos kolwa, elite cristã africana de Natal (HUGHES, 2001; 2011).

O poeta zulu B. W. Vilakazi (1906-1947), que faleceria, precocemente, no ano seguinte à morte de Dube, dedicou-lhe um tributo no qual o inscrevia como "the moving soul in the national unity in South Africa". Vilakazi que, em março daquele mesmo ano, se tornaria o primeiro sul-africano negro a concluir um doutorado, defendendo a tese Oral and written literature in Nguni na Universidade de Witwatersrand, destacava 
ainda, a exemplo de Sivetye (1946), que a "political leadership [de Dube] was at a time when co-operation between White and Black in South Africa was taboo" e que Dube ficaria feliz em ver "the racial harmony slowly growing within some South African Universities" (VILAKAZI, 1946, grifo nosso).

Mas esse esboço de identidade nacional fundado em integração e harmonia interracial seria logo obliterado pelo advento do Apartheid, o "mais restritivo de todos os sistemas de discriminação racial, legalizada da história recente” (STONE, 2008, p. 17), "um dos regimes mais violentos e repressores da história mundial contemporânea" (BARBOSA, 2015, p. 191).

\section{Dube na África do Sul do Apartheid}

Ainda nos 1940, o contemporâneo de Dube, Sivetye e Vilakazi, o sociólogo G. Cronjé (1907-1992), sistematiza a ideia de que a variedade da criação resulta da natureza e da vontade divina, causando prejuízo irreparável situações de mistura e contato. Discurso de origem acadêmica, elaborado por um branco, o Apartheid se ocupa, sobretudo, com o destino de populações não-brancas, tornando-se base de políticas estatais de construção da nação na África do Sul (ROSA RIBEIRO, 2002, p. 486). No contexto do Apartheid, que consistiu num projeto forjado através de uma série de esforços dentro e além do estado, que forçaram os arquitetos das políticas estatais a revisar muitas de suas estratégias originais (POSEL, 1991), os intérpretes de Dube, muitas vezes, parecem estar menos interessados no próprio Mafukuzela do que nas causas da institucionalização da segregação racial.

Em maio de 1948, o Partido Nacional, defensor do regime de separação racial, saiu-se vitorioso das eleições gerais, que barraram a participação de sul-africanos de origem não europeia. No mês seguinte, em carta endereçada a Nelson Mandela, o líder político I. B. Tabata (1909-1990), que fundara, em 1943, o Non-European Unity Movement (NEUM), organização de caráter trotskista, reconstruindo e prospectando a organização desse movimento e das lutas de libertação na África do Sul, salienta que a administração branca teria reagido à criação do NEUM, encontrando "a willing stooge in the person of the late Dr. Dube, at that time, Mr. Dube, a principal of some secondary school in Natal", "the first one to break away from Convention, and with him went practically the whole of Natal. The White Press acclaimed him as a great statesman, a moderate, a practical politician and in fact an epitome of all virtues". Os brancos "crowned him with a halo of greatness and conferred a doctorate on him. It was as Dr. Dube that he led the Zulus back to tribalism, where they still stagnate today". (TABATA, 1948)

Nos anos 1970, quando, na África do Sul, começa a florescer uma história revisionista e uma historiografia social crítica, aparecem importantes interpretações acadêmicas sobre Dube, que serão retomadas com o fim do Apartheid, tendo papel-chave na consolidação de determinados modos de apreendê-lo tanto no campo da escrita histórica profissional quanto no âmbito da história tornada pública. 
O foco nas relações de Dube com o cristianismo americano e com B. T. Washington consistiu na questão central da primeira interpretação propriamente historiográfica sobre Langalibalele, publicada pelo professor norte-americano R. H. Davis Jr., em 1975, no Journal of African Studies. Para Davis Jr., Dube teria adotado, conscientemente, a filosofia e as estratégias de Washington, tendo ficado muito impressionado com seu programa educacional que combinava formação industrial e agrícola e educação acadêmica, e enfocava ideias e práticas de desenvolvimento de autossuficiência, trabalho manual e formação do caráter (DAVIS JR., 1975, p. 505). Este tipo de formação, na visão de Dube, seria ideal para a construção de autoconfiança entre os africanos, fundamental para seu desenvolvimento econômico. Davis Jr. salienta ainda que, embora Dube tenha sido eleito presidente do ANC, ele fôra afastado por sua aparente aceitação do princípio geral da segregação, embora se opusesse às práticas concretas de Apartheid (DAVIS JR., 1975, p. 497, 519). E sugere que, muito provalmente, Dube era bem visto e aceito entre brancos moderados de Natal por sua defesa da autossegregação dos africanos, já que era a favor de desenvolver escolas para negros (DAVIS JR., 1975, p. 518).

A historiadora sul-africana S. E. Marks, atualmente reconhecida como uma espécie de "godmother of Southern African History" (SOUTH AFRICA..., 2017), argumentara, num texto exporatório, que a vida de John Dube "expresses and reflects some of the complexities" da região de Natal, marcada por "some of the most ambiguous patterns of leadership" e onde "some of the most dramatic grassroots resistance to White rule in 20th century South Africa has come from". Para Marks, "in Natal the contradictions between theory and practice, between the exploitation, expropriation and political supression of Africans on the one hand, and the ideology of separate development, paternalism and trusteeship on the other, have probably been more blatant than in any other part of South Africa in the first half of the twentieth century". (MARKS, 1975, p. 162-163)

Segundo Marks, as próprias transformações sociais que marcaram a história de Natal e da África do Sul teriam desafiado as estratégias e a ideologia de John Dube, especialmente nos últimos anos de sua vida. Dube teria testemunhado as mudanças dramáticas na vida africana em direção à industrialização. Ainda jovem, Langalibalele teria assistido à destruição da independência zulu, a transformação do zulu autodefinido como guerreiro em um zulu, agora, servo dos europeus, de homens camponeses independentes em despossuídos rurais e subassalariados urbanos. Apesar de ter rejeitado o liberalismo com seu eurocentrismo, Dube também teria tentado advogar uma solução de classe média (as virtudes da economia e da indústria, educação e acumulação do capital), mas não se tornou um real potencial líder para o emergente proletariado urbano e a nova classe média. Embora, até o fim da sua vida, ele pudesse ter posições críticas em relação aos brancos e ao sistema do Apartheid, a partir dos anos 1930, acabou não correspondendo ao estado de espírito dos novos líderes e de seu novo público urbano. Provavelmente, isto se deu devido à sua não aceitação da violência (talvez a lição aprendida com a Rebelião Bambata, revolta zulu contra a conbraça de impostos e a colonização, ocorrida em 1906, marcada pela dura repressão sendo seus líderes assassinados), à sua visão de mundo profundamente enraizada em 
concepções de lei e ordem (resultado do seu pertencimento à sociedade tradicional zulu e à educação missionária que recebeu) e, também, à sua vinculação às elites. (MARKS, 1975, p. 165-166)

Ainda para S. Marks, nos primeiros anos do século XX em Natal, as declarações de Dube por igualdade racial, por justiça e por unidade africana podiam ser vistas como revolucionárias, já que desafiavam diretamente o poder branco na colônia. Contudo, argumenta a historiadora, a identificação das ideias de Dube com os princípios segregacionistas precisam ser consideradas. Marks retoma, então, um dicurso de Dube, realizado em 1925, em Joanesburgo, durante a Conferência Missionária, em que tratava do processo de urbanização e industrialização pelo qual passava a África do Sul, argumentando que "raw natives suddenly coming face to face with European civilization totally unprepared for the evils wh. civiliz. cause in its train, unaware of its pitfalls, getting more in touch with the lower classes of European rather than the best". Para Marks, neste discurso, "the similarity with contemporary white liberal segregationist thought - and indeed with Washington - is heavily marked”. (MARKS, 1975, p. 165-166) Marks também lembra que Dube "himself had been ousted from the presidency of the ANC in 1917 for his apparent acceptance of the principle - if not the con-temporary South African practice - of segregation, this was probably the most controversial of Dube's actions" (MARKS, 1975, p. 176). E, no início dos anos 1930, Dube "entered into an alliance with the segregationist, Heaton Nicholls, at this time a key spokesman on 'racial affairs', an ardent exponent of the philosophy of 'development along their own lines'” (MARKS, 1975, p. 178).

Enfim, Marks interpreta a vida de John Dube como existência encapsulada pelo seu tempo, incapaz de negociar com o radicalismo urbano que emergiu na África do Sul nos anos após a Primeira Guerra Mundial. Dube teria respondido pela adoção de uma abordagem étnica que, ao fim, acordou com o pensamento segregacionista e serviu para subvalorizar a solidariedade de classe e, portanto, contribuíra para a consolidação do Apartheid. Em Marks, parecem coexistir, de um lado, a objetividade da ciência histórica fundamentada em evidências e na eficiência dos instrumentos metodológicos e, de outro, a claro apreço pelo desenvolvimento histórico que se define, antes de tudo, pelas formações e lutas estruturadas em torno da classe e não, por exemplo, da solidariedade e da identidade racial.

O afro-americano W. M. Marable (1950-2011), crítico do afrocentrismo e que se tornaria professor de estudos afro-americanos da Universidade de Colúmbia, defende, em 1976, sua tese de doutorado sobre a vida de John Dube, na Universidade de Maryland. Marable, cujos pais estudaram na Universidade Central State, instituição historicamente negra em Ohio e que, aos 17 anos, fez a cobertura do funeral de M. L. King Jr. para o jornal da comunidade negra da cidade de Dayton, apresenta uma interpretação que, embora guarde semelhanças com aquelas de Tabata, Marks e Davis Jr., é bem mais crítica e ácida em relação a Dube.

Para Marable (1976), a vida de Dube e da cultura e sociedade na qual ele alcançou a maturidade ajuda a explicar as trágicas e cruéis relações raciais que estão no centro da vida moderna sul-africana. Os americanos teriam provido John Dube com uma 
ideologia progressista para levar a elite kholwa de um estado pré-industrial à cultura burguesa. Os missionários congregacionais americanos teriam produzido um jovem negro que acreditava em uma ética do trabalho calvinista e na educação industrial para os africanos. As viagens de Dube para os Estados Unidos entre 1887 e 1889 teriam estabelecido o pressuposto fundamental de seu pensamento educacional e político. Viajando através do cinturão negro do sul norte-americano, Dube teria sido munido pela crença firme na filosofia Tuskegee, de Booker T. Washington: self help racial e nacionalismo econômico. Embora Dube tenha tentado ativamente fomentar, para os africanos, oportunidades sociais dentro do sistema colonial, acreditando na África para os africanos, ele, no entanto, ao longo de sua vida, teria desenvolvido uma prática política profundamente conservadora. Dube teria se oposto aos sindicatos e aos militantes, a Gandhi e aos radicais do ANC. Sua oposição ao Natives Land Act de 1913 teria se dado não como crítica à segregação das raças, mas porque limitava severamente a capacidade dos kholwa em possuir propriedade. Dube estaria, enfim, apenas preocupado em encontrar caminhos para o progresso social e econômico da elite africana da qual fazia parte. Dube se tornou, ao fim da vida, o símbolo do líder africano paciente e conservador, obediente às leis.

Em síntese, Langalibalele, segundo Marable, "was a creation of the British colonial system and American thought". "His failure [...] to appreciate the corrupt character of segregation and to oppose White racism at all levels, helped to bring about the system of South Afriacn race relations called apartheid". Para Marable, "because of their acceptance of segregation, the basic principle of apartheid", a geração de Dube "could never achieve what they ultimately desired above all else - the recognition of their full civil rights as human beings". (MARABLE, 1976, p. 367) Fundamentalmente, "the personal history of Dube is, more generally, the story of a defeat of the human spirit. The major goals which Dube and his political friends pursued and the short range tactics of Natal's small Black midlle classe helped to create the anti-humane regime in southern Africa". (MARABLE, 1976, p. iii).

Entretanto, conectando-se a rememorações como as de Wilcox (1927) e Vilakazi (1946), há outros lugares sociais nos quais Dube é resgatado ainda durante o Apartheid, como aqueles da tradição oral, onde "a palavra tem um poder misterioso, pois palavras criam coisas” (VANSINA, 2010, p. 140). Em 1962, o Instituto Ohlange passou a realizar a Mafukuzela Week. Em 1974, o poeta e imbongi Mbutho recitara, no túmulo de Dube, um izibongo, em sua homenagem. Constituído por 485 versos, nesse izibongo, que foi reproduzido, no mesmo local, em 1992 (NZANA, 1992), rememoram-se os feitos de Dube como armas poderosas na batalha pelo progresso e libertação da África e na luta contra o racismo e a favor da construção de um mundo igualitário (BARROS, 2018b).

O imbongi Mbutho, que recitara o izibongo de Dube em 1974 e 1992, era um poeta que trabalhava com a tradição zulu estabelecida, especialmente aquela de matriz oral, e produzia izibongo para diversos líderes africanos do passado, sobretudo chefes do povo qadi, como Dube, Silwane, Dabeka e Mqhawe, e ainda reis zulus como Shaka, Dingane e Senzangakhona (NZANA, 1992, p. 71). O izibongo de Dube se autoproclama como meio através do qual os zulus "size singaloni isiko lokukhulama nabaphansi 
[não deixam interromper o costume de dialogar com os ancestrais]" (IZIBONGO, 1974). Mbuto, evidentemente, não é historiador de ofício, como S. Marks (1976) e Marable (1976) não são poetas. E, talvez, o izibongo de Dube esteja mais para "uma espécie de psicodrama que revela à comunidade suas raízes e o corpo de valores que sustenta sua personalidade: um viático encantado para singrar o rio do tempo em direção ao reino dos ancestrais", sendo, exatamente por isso que "a palavra épica não coincide exatamente com a palavra histórica” (KI-ZERBO, 2010, p. XXXIX). Apesar disso, cabe lembrar que qualquer sujeito é aproximado de um historiador pela experiência da releitura, que é apenas um exemplo da dificuldade, senão da impossibilidade, de reviver o passado (HALBWACHS, 2006). Desse modo, o izibongo de Dube poderia ser interpretado como uma etapa próxima àquela do trabalho da própria memória em si, o que ocorre cada vez que uma memória está relativamente constituída, quando ela efetua um trabalho de manutenção, de coerência, de unidade, de continuidade, da organização (POLLAK, 1992, p. 7).

O izibongo oferece uma rememoração das ações políticas e religiosas, das qualidades pessoais e também a avaliação de Dube feita por seus contemporâneos. Os eventos são narrados cronologicamente, do nascimento à morte de Dube. O izibongo começa com algumas lamentações acerca de sua morte. Inicialmente, indica-se que a morte de Dube retirou do meio do povo um dos maiores filhos da África. Mostram-se as dificuldades que ele teve durante sua vida. Apresenta-se Dube como um homem que superou significativos obstáculos, trabalhado nos bons e maus momentos pela grandeza do continente africano. Destaca-se que suas atividades políticas se estenderam para diversos lugares, como a Suazilândia, Lesoto, Rodésia e outras partes de África, e que Dube percebera que nenhum povo podia confiar inteiramente em meios de comunicação controlados pelos brancos, por isso fundou llanga lase Natal, para, assim, apresentar as aspirações e esperanças dos zulus e africanos. Afirma-se que esse jornal se tornou um dos meios de comunicação mais importantes para a expressão dos pontos de vista dos povos africanos negros, uma arma poderosa na batalha pelo progresso e libertação de África. Considera-se ainda que todos os africanos, dos mais importantes aos mais humildes, rurais e urbanos, zulus e não zulus, falariam com respeito e gratidão de Dube. Lembra-se que a Organização Nacional Africana deu-Ihe um lugar de honra devido a tudo o que fez. Destaca-se que mesmo os seus inimigos e opositores, as autoridades governamentais, muitas vezes, buscavam o seu conselho e cooperação nas questões africanas.

Pontua-se que Dube se tornara um símbolo nacional de tudo o que é grande, duradouro, bom e evidência de progresso e, como educador, teria percebido que o estado educacional das massas deveria ser elevado. Para tanto, construíra uma escola na qual os africanos aprendiam e ensinavam uns aos outros. Pondera-se que Dube enfatizou a necessidade de educação técnica para os africanos e acabou sendo mal interpretado por alguns, que o acusaram de pensar que o negro só estaria preparado para um papel que envolvesse o uso de suas mãos, em vez de sua mente. Salienta-se que Dube realizara mais feitos do que Booker Washington. Lembra-se que as atividades políticas e educacionais de Dube tiveram impacto na Rebelião Bambatha e que o Instituto Ohlange formara estudantes de vários grupos étnicos, tendo, portanto, Dube 
construído uma escola para toda a África. Destaca-se a produção escrita de Dube bem como a importância da ancestralidade, da comunicação através da palavra. Evidenciase também a sua luta ao longo da vida por igualdade e unidade entre os africanos.

Enfim, aqui, Langalibalele é, antes de tudo,:

Baba We-Africa
Mfundisi We-Africa
Mamonga We-Africa lanamuhla
Qhawe lamaqhawe
(Izibongo, 1974)
[Pai da África
Professor da África
Edificador da África de hoje
Herói dos heróis]

É significativo observar que o izibongo de Dube, realizado durante o Apartheid, para além da reificação de Dube como herói e mito, se apropria e instaura uma espécie de memória social que pensa a África do Sul em termos de busca da liberdade, dos grandes nomes do continente africano, da grandeza de África, da esperança no progresso, no diálogo com a ancestralidade e na construção de um mundo antirracista. O izibongo de Dube não é construído sob a retórica do sofrimento como questão primeira, como seriam as recordações estimuladas no âmbito da TRC, estabelecida em 1996 (GROSSMAN, 2000), que parecem evocar mais a memória da vitimação, perspectiva que pode levar a imaginar a população sul-africana negra como não sujeito e agente da história. Para além do clássico argumento freudiano acerca do caráter ferido da memória cujos mecanismos complexos tendem a recalcar os traumatismos sofridos e as lembranças muito dolorosas (FREUD, 1972), é possível sugerir que as formas de se apropriar e rememorar os eventos do passado eram diversas mesmo naqueles tempos de segregação oficial.

Capítulo de uma "memória subterrânea" (POLLAK, 1989, 1992), antes restrita a espaços mais privados, como sua família e setores sociais mais próximos, essa imagem-memória da vida e obra de Dube e de seus feitos será dominante nas formas de apreendê-lo na África do Sul pós-Apartheid.

\section{Dube revivido na Rainbow Nation}

Em 1994, nas primeiras eleições gerais da história da África do Sul democrática, Nelson Mandela votara no Instituto Ohlange. Maior ícone da Rainbow Nation, um de seus símbolos e seu principal idealizador, Mandela também escolheu o túmulo de Dube para fazer seu primeiro pronunciamento, de agradecimento, pela vitória, afirmando: "Mr. President, I have come to report that South Africa is now free" (OBERLIN-INANDA, 2006). 


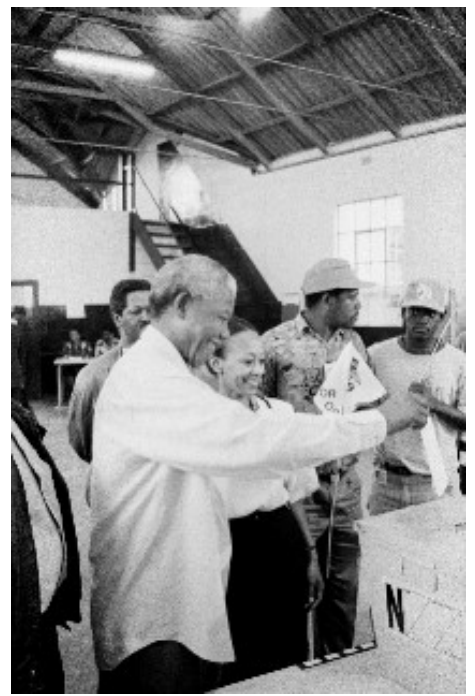

Figura2: Nelson Mandela votando em 1994

Fonte: https://www.nelsonmandela.org/images/uploads/Nelson_vote1.jpg ${ }^{8}$

Mafukuzela, também no ambiente acadêmico, passa a ser reinscrito. Em 1999, o professor zulu E. D. Gasa, já na epígrafe de sua tese de doutorado em história, defendida na Universidade da Zululândia e voltada para a atuação política de Dube, inscreve-o como lqhawe Le Afrika (Herói da África), "the hero of our land", que "made contributions to mankind" (GASA, 1999, p. viii-ix). Dube é re-conectado ao humanismo no mesmo movimento em que se destaca que ele "demanded and fought for equality, justice and African unity" (GASA, 1999, p. 325).

Gasa (1999, p. xxi) reconhece, brevemente, que Dube "remained a figure of controversy throughout his illustrious social and political career" e que "late in life, especially after 1917, Dube was criticized and eventually ostracised, for his political standpoint on the principle of segregation in land opporitionment, and was consequently been referred to as well as 'sell-out' as 'compromiser' or 'political accommodationist", de modo que "he acquired the reputation of having 'sold out' the African nationalist movement". Apesar disso, a personagem Dube, de Gasa, ao fim e ao cabo, não é em nada ambígua como aquela de Marks e Davis Junior e, muito menos, o exemplo de um fracasso pessoal e social que teria contribuído para a implementação do Apartheid, como em Marable ou Tabata.

Fundamentamente, para Gasa, Dube pôs-se a tarefa de revelar as falhas do sheptonism $^{6}$ e sua política abusiva de cobrança de impostos, o que levara "his activities drew the extreme ire of the whites and government officials who constantly viewed him with suspicion" (GASA, 1999, p. 2); foi hábil na identificação do tipo de 
reformas e mudanças que os africanos desejavam, envolvendo-se, firmememnte, na política, quando necessário; organizou, com sucesso, os africanos cristãos, sendo ele "deeply committed to non-violent change" (GASA, 1999, p. 98); pretendeu que, nas suas relações com os africanos, o governo fosse justo, objetivo e humano; protestou contra a subjugação dos africanos pelo governo colonial, preferindo que os africanos fossem consultados em relação a decisões que diziam respeito às suas vidas; lutara para que os africanos fossem elevados à escala da civilização; defendeu que a terra fosse distribuída de forma equitativa; exigiu um sistema de ensino completo para os negros que promovesse todas as suas características humanas; instou o governo para sustentar financeiramente e controlar a educação africana, não deixando isso para as sociedades missionárias; e pressionou pela emancipação e representação dos africanos no poder legislativo de Natal.

Certamente, M. Marable (1976) estaria de acordo com Gasa, para quem Dube foi uma das figuras políticas africanas mais importantes em Natal do primeiro terço do século $X X$, sendo "product of his times, so his personality, political views and actions were a direct outcome of what was happening around him. The events of the time determined and influenced his reaction". Contudo, diferentemente de Marable, em Gasa, o que se torna significativo é destacar que Dube teria usado sua força política e influência para moldar e tentar mudar o curso dos acontecimentos. $E$ "even though he did not succeed in all instances, he found solace in that he had committed himself to and contributed much to the defence of Africans against white avarice, injustice, mismanagement, domination and subjugation, while protecting the Africans themselves against self-destruction and selfeffacement”. (GASA, 1991, p. 1)

Em 2003, a UKZN, em colaboração com o Conselho Cristão de Kwazulu-Natal, começou a realizar eventos, especialmente aulas públicas, em memória de Dube. Trata-se de ocasiões de caráter, claramente, pedagógico. Nelas, a história é pretendida, antes de tudo, como magistrae vitae (KOSELLECK, 2006), afinal, a memória, onde cresce a história, que por sua vez a alimenta, procura salvar o passado para servir o presente e o futuro (DOSSE, 2003). Na primeira delas, ministrada pelo professor zulu R. Kumalo (2011; p. 13; 21), salienta-se que Dube dera "a tremendous contribution in bringing down colonization and apartheid". Assim, trata-se de "learning from the past so as to understand the present and shape the future of the African people". "Providing a brief biography of Dube", Kumalo buscou, fundamentalmente, identificar "some of the key themes found in his legacy which can be useful for the present context and also in the future as we continue building the new South Africa".

Kumalo (2011, p. 18) lembra que a luta pela democratização da África do Sul foi influenciada por fatores políticos, teológicos, culturais e humanitários, tendo a religião, especialmente o cristianismo (embora não exclusivamente), desempenhado um papel muito importante como locus no qual surgiram os defensores da democracia e da liberdade. Dube é aqui, apresentado, como um cristão africano que trabalhara pela liberação política para si e para seu povo. Kumalo lembra a argumentação de alguns estudiosos de que a elite educada nas missões cristãs não ameaçava a hegemonia colonial, porque agia de modo moderado. Assim, “Dube's legacy is sometimes blurred 
by the accusation that he had compromized liberation principles by accepting some of the principles of segregation". Ele "was accused of speaking in a modulated voice because he spoke of Christianity, civilization, self-reliance and non-violence". Mas, "such accusations are misplaced and stem from his critics' misunderstanding of his theology of liberation and decolonization". A teologia de Dube seria baseada em princípios cristãos e em perspectivas culturais africanas, especialmente de raízes zulus. "There is a sense”, argumenta Kumalo (2011, p. 35-36), "in which Dube's understanding of himself and his place in society as a Black African person, as well as his attempt to contribute to the struggle against the colonization of the people's land, rights and minds, is even more relevant today in the formation of the nascent South African nation".

No contexto da celebração dos 100 anos do ANC, em 2012, proliferariam narrativas sobre Dube, incluindo a mais completa biografia sobre ele, intitulada First President: a life of John L. Dube, founding president of the ANC, publicada em 2011. Nesta escrita histórica, produzida por $\mathrm{H}$. Hughes que, durante anos, manteve contato com a família de Dube, também se torna basilar demarcar o legado de Mafukuzela para os tempos atuais.

Hughes (2011, p. xiii-xix), a exemplo de outros biógrafos de Dube, nota que o contexto no qual ele viveu foi o da revolução industrial da África do Sul. Para a historiadora, a visão de mundo de Dube, na qual havia uma crença implícita na marcha contínua do progresso humano para o esclarecimento, era estruturada de modo a possibilitar que se engendrasse uma forma de mudança social dirigida pelos valores do mercado e do cristianismo. Ele era consciente acerca de quão radical eram suas ideias de progresso social e, portanto, queria introduzi-las de um modo altamente disciplinado e controlado. Seu senso de modernidade, além disso, incluía não somente um orgulho intenso de sua raça (e, crescentemente, uma defesa desta sob as políticas segregacionistas contemporâneas), mas também uma ordem social hierárquica estrita, uma espécie de meritocracia e aristocracia combinadas.

Para Hughes (2011), foi de Dube e de seus partidários que muitas pessoas comuns do campo em Natal ouviram pela primeira vez a proposição extraordinária de que os africanos deveriam ter o direito de votar diretamente para os representantes do Parlamento. Uma vez que pagavam tanto imposto, eles tinham o direito de ter terra suficiente para as suas necessidades, de ganhar salários decentes e obter educação.

Aqui, Dube é filho da convicção no progresso e no autoaprimoramento. Destaca-se que, partindo de uma tradição republicana, ele desenvolve uma política oposicionista e, fortemente, cívica para alcançar direitos individuais e coletivos. Ao mesmo tempo em que é crítico do paganismo e dos chefes tradicionais que mal governam os seus, ele tem orgulho de sua herança cultural. (HUGHES, 2011, p. 256) Retomar o legado de Dube significaria tanto reconduzi-lo ao seu próprio tempo quanto conectá-lo, diretamente, às agendas do tempo presente: cidadania, multiculturalismo, antiracismo e humanismo.

O malinês C. Keita, professor de literatura francófona do Carleton Collegge (EUA) e documentarista, produziu, entre 2009 e 2010, uma trilogia de documentários sobre Dube. Wilcox-Dube, an American-South African story on the screen, o primeiro deles, 
reconstrói o encontro do jovem Dube com Wilcox, hoje visto como homem que contribuiu "to the struggle of the African people for self-determination" (KUMALO, 2013). O encontro é reproduzido por Keita, que acaba se tornando, ele próprio, um importante "empreendedor de memória" (JELIN, 2002, p. 49) da África do Sul pósApartheid. Durante a gravação do documentário em Natal, no ano de 2007, Keita promoveu o encontro de alguns membros das famílias Dube e Wilcox: Jackson Wilcox, neto dos missionários Wilcox, Deborah, sua bisneta, e Zenzele Dube, neto de John Dube. O encontro de Dube com o casal Wilcox no final do século XIX é retomado como momento crucial para a evolução social da nação sul-africana hodierna: exemplo da possibilidade de entendimento entre brancos e negros.

O segundo documentário, Oberlin-Inanda: the life and time of John Dube, reconta a vida e a jornada política do homem Dube. Finalmente, Cemetery Stories: a Rebel Missionary in South Africa, foca na família Wilcox, interpretando seus membros como missionários não convencionais, que teriam ficado do lado dos negros contra o sistema colonial. Não por acaso, em 2009, o governo sul-africano concedera o maior título honorário da África do Sul, a Grand Compannions of O. R. Tambo, ao Rev. Wilcox, "for his contribution to the fight against colonial oppression and racism" (ZUMA, 2012b).

Em janeiro de 2012, Dube foi o primeiro dos doze presidentes homenageados pelo ANC nas comemorações dos seus 100 anos de existência. A cerimônia foi transmitida ao vivo pela SABC, televisão pública e aberta sul-africana e reproduzida pela internet. Langalibalele, de certo modo, sai de uma relativa invisibilidade para uma hipervisibilidade, é transformado em aspecto da cultura nacional sul-africana. Na cerimônia, o então presidente da África do Sul, J. Zuma (2012a) afirmara que "President Dube's legacy encapsulates African unity, self-reliance, quality education and a tireless fight for equality and freedom". Mafukuzela "articulated an African identity that transcended tribal identities". Apesar de todas as ideias em contrário, "Dr. Dube remained convinced of the need to establish racial harmony". (ZUMA, 2012b)

Nesse mesmo ano, aos 17 de maio, ocorre a cerimônia de renomeação da residência oficial da presidência e vice-presidência da república da África do Sul. A antiga King's House passaria a se chamar Dr. John Langalibalele Dube's House. A mensagem manifesta é de que "this exercise will promote national healing and reconciliation", "the objective of this process is not to obliterate the history of any section of our society", mas "to contribute towards building an inclusive society which acknowledges our common heritage, nationhood and destiny". Destaca-se que "only those who are in denial about the inhuman practices and atrocities perpetrated against indigenous populations by colonial powers in every part of the world would think that the exercise we are embarking upon is not necessary and important". Ora, "there has to be recognition of the realities of the horrible period of colonization and apartheid". Além disso, "the renaming process will help to restore a sense of identity and national pride amongst our people and will also assist in the reconstruction of the history of many places in South Africa". "Join us in celebrating this indigenization of South Africa". (THE PRESIDENCY, 2012) Como se sabe, tornarem-se senhores da memória e do esquecimento é uma 
das grandes preocupações das classes, dos grupos, dos indivíduos que dominaram e dominam as sociedades históricas. (LE GOFF, 1992, p. 426)

A ideia de preservar, restaurar e promover o patrimônio da África do Sul faz parte das políticas governamentais pelo menos desde que Mandela assumiu o governo sul-africano em 1995. O governo organizara, por exemplo, o Heritage Project, no qual se desenvolveram 28 projetos sobre patrimônio em todo o país prestando-se homenagem àqueles identificados como heróis e heroínas da luta contra o Apartheid.

Em 1995, a casa de Dube foi tornada Patrimônio Nacional e, em 2010, inaugurou-se The Inanda Heritage Route, em Durban, com uma estátua de Dube em destaque: "it is where the seeds of the country's liberation were planted; a valley imbued in history that explores both sung and unsung African heroes".7

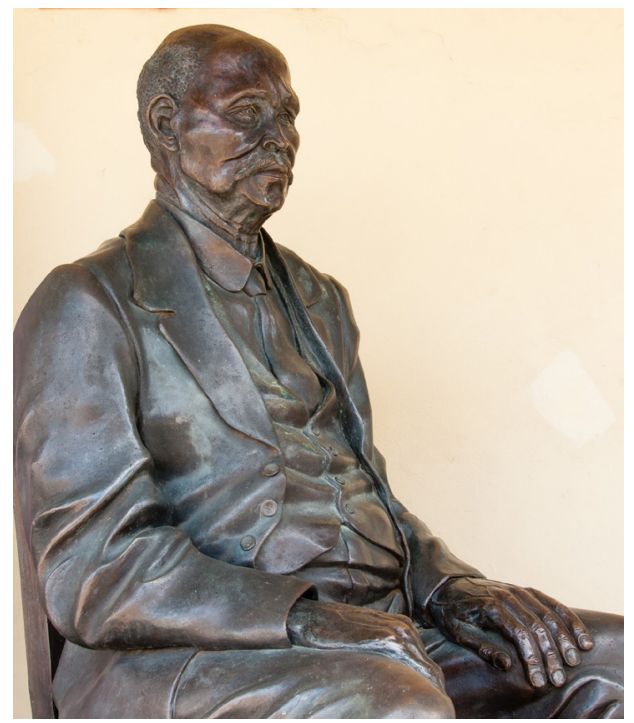

Figura 3: Estátua de John Dube

Fonte: http://blog.sa-venues.com/provinces/kwazulu-natal/the-inanda-heritage-route/ ${ }^{9}$

Na South African History Online (SAHO), que se apresenta como uma organização sem fins lucrativos ou vínculos partidários, embora seja vinculada ao Governo da África do Sul, criada em 2000 com a missão oficial de "to address the bias in the way South Africa's history and heritage, was represented under colonialismo and apartheid in our educational, cultural and heritage institutions", há uma seção destinada a John Dube, que é biografado. Aqui, Dube é, essencialmente, educador, político, autor, ministro da Igreja Congregacional, membro-fundador e primeiro presidente do ANC. 
Alguns elementos devem ser destacados no breve texto da SAHO resumindo a vida e obra de Dube. Claramente, tenta-se distanciar Dube de qualquer relação com a ascensão do Apartheid ou com ambiguidade tanto na luta contra a segregação e pela liberdade quanto na conexão com as ideias e práticas identificadas como negroafricanas. Assim, afirma-se que, se, de início, o estabelecimento do Instituto Ohlange foi permitido pelo governo, posteriormente, esta postura mudara, pois os brancos estariam temendo cada vez mais a concorrência dos negros e indianos. Destaca-se ainda que "Dube bitterly opposed the arrest and trial of Dinizulu in conexion with the rebeletion [Bambata, 1906] and actively assisted in raising funds for his defence". Dinizulu era "son of the last Zulu king, was for Black people in South Africa the symbol of their former independence and their identity as a people. Dube, with his recollections of and pride in his African past, understood the significance of Dinizulu and his place in Zulu history". Salienta-se que quando Dube voltou dos Estados, em 1905, houve tensão entre ele e os missionários brancos. Através de llanga lase Natal, Dube atacou algumas decisões dos missionários, particularmente, sua não defesa dos interesses africanos. Por criticar as legislações propostas pelo governo, Dube fora frequentemente advertido de que estaria brincando com fogo. Lembra-se ainda que aqueles que vêem contradição na geração de Dube, pois se converteram psiciologicamente ao cristianismo, devem também lembrar que o impacto dessa religião na cultura e no sistema de valores africanos é superficial no continente. Além disso, os brancos suspeitavam do etiopianismo de Dube: ora, se por etiopianismo, os brancos entendiam que Dube e seus colegas estavam determinados a provar e demonstrar aos brancos que o homem negro pode levar adiante uma instituição educacional sem qualquer assistência dos brancos, então se deveria estar de acordo com eles. Por fim, é importante salientar que quando se menciona Tabata, que afirma ser Dube um fantoche nas mãos dos brancos, há o cuidado de se sugerir que esse seria o "characteristic style and fashion" do líder revolucionário, isto é, tal caracterização teria menos a ver com Dube do que com o próprio Tabata. (BIOGRAPHY, 2011)

\section{Considerações finais}

Na década de 1980, durante a guerra civil, as divisões ideológicas da região de Kwazulu-Natal se tornaram ainda mais agudas. Neste contexto, foram intensos os conflitos envolvendo os apoiadores do ANC e do Inkatha (Inkatha Freedom Party), o que resultara em centenas de mortes. Apesar disso, há indícios de que, não apenas o ANC, mas também o Inkatha reivindicara a herança de Dube (HUGHES, 2011, p. 261). As origens e o desenvolvimento do Inkatha se relacionariam mais ao deliberado renascimento da família real zulu, em formas tradicionais, do que à reação espontânea do povo zulu. Fundado em 1922-3, por um grupo de conselheiros de Solomon e por um grupo dos kholwa, incluindo John Dube, o Inkhata teria sido uma tentativa deliberada de se usarem formas tradicionais na criação de um conselho de chefes na Zululândia (COPE, 1990; MARKS, 1977). No izibongo de Dube, nos anos 1970, relaciona-se Dube ao nascimento do Inkata, mas, posteriormente, ao contrário do ANC, o Inkhata parece se distanciar de Dube. 
O fato é que tudo acontece como se esses discursos e imagens, presentes e ausentes, sobre Dube servissem tanto para ativar problemáticas em voga na África do Sul como, simultaneamente, para legitimar as continuidades ou mudanças de orientação política na cena pública.

Cabe ainda ressaltar que, se as percepções sobre a existência de Dube são variadas, todos os biógrafos, documentaristas e comentadores concordariam em ao menos dois pontos. De um lado, ele não se confunde com um indivíduo ordinário ou socialmente insignificante, o que ajuda a explicar a profusão de dispositivos empregados para produzir, atualizar ou questionar o legado desse personagem. De outro lado, devido a essa primeira dimensão, uma vez liberado da condição estritamente biológica, a existência de Mafukuzela pode, então, assumir uma dimensão pública, permitindo a sua utilização como objeto de diferentes estratégias e tramas de competição política e batalhas pela memória e pela construção da nação.

\section{Referências}

ANDERSON, B. Nação e consciência nacional. São Paulo: Ática, 1983.

APPIAH, K. A. Na casa de meu pai: a África na filosofia da cultura. Rio de Janeiro: Contraponto, 1997.

BALAKRISHNAN, G. (org.). Um mapa da questão nacional. Rio de Janeiro: Contraponto, 2000.

BARBOSA, V. de O. Políticas Sociais e Legislação no Apartheid Sul-Africano. Outros Tempos, v. 12, n. 19, 2015.

BARROS, A. E. A. Cultura, Patrimonialização e Desigualdade no Brasil e na África Austral. Revista de Politica Públicas, v. 22, pp. 43-64, 2018a.

Um izibongo para Mafukuzela: Memória, História e Nação na África do Sul. Outros Tempos, v. 15, pp. 108-121, 2018b.

. Entre o kraal e a terra iluminada: as Áfricas do jovem John Dube. In.: TRAJANO FILHO, Wilson. Travessias Antropológicas: estudos em contextos africanos. Brasília: Aba Publicações, 2012.

BATES, R.; MUDIMBE, V.Y; O'BARR, Jean. Africa and the Disciplines. Chicago: UCP, 1993.

BHEBE, N. Os britânicos, os bôeres e os africanos na África do Sul, 1850-1880. In.: AJAYI, J. F. A. de. História geral da África, VI. 2. ed. Brasília: UNESCO, 2010.

BIOGRAPHY. John Langalibalele Dube. Disponível em http://www.anc.org.za/ showpeople.php?p=31. Acesso em 10 de out. 2011.

BOURGAULT, L. M. Mass Media in Sub-Saharan Africa. Bloomington; Indianapolis: IUP $<1995$. 
CELL, John. The origins of segregation in South Africa and the American South. Cambridge: University Press, 1982.

CHANAIWA, D. Iniciativas e resistências africanas na Africa meridional. In.: BOAHEN, A. A. História geral da África, VII. 2. ed. Brasília: UNESCO, 2010.

COETZEE, R. M.. The mind of Apartheid. Geoffrey Conjré (1907-), Social dynamics, n. 17, p. 1-35, 1991.

COMAROFF, J.; COMAROFF, J. L. Theory from the South: Or, how Euro-America is evolving toward Africa. Anthropological Forum, V. 22, N. 2, July 2012.

COPE, Nicholas. The Zulu Petit Bourgeoisie and Zulu Nationalism in the 1920s: Origins of Inkath. Journal of Southern African Studies, V. 16, n. 3, p. 431-451, 1990.

CRITTENDEN, W. B. Letter. In.: DUBE, J. L. A familiar talk upon my native land and some things found there. [s. e.], 1891.

DAVIS JR., R. H. John L. Dube, a South African Exponent of Booker T. Washington. Journal of African Studies, 2 (4), 1975-6.

DINNERSTEIN, M. The American Zulu Mission in the Nineteenth Century: Clash over Customs. Church History, 45(2): 235-246, 1976.

DOSSE, François. A História. Bauru:Edusc/SP, 2003.

DUBE, J. L. A familiar talk upon my native land and some things found there. [s. e.], 1891. Segregation. Natal, 1914 (Killie Campbell Collection).

FOSTER, F. H. Letter. In.: DUBE, J. L. A familiar talk upon my native land and some things found there. [s. e.], 1891.

FREUD, Sigmund. A Interpretação dos Sonhos. Rio de Janeiro: Imago, 1972.

FRY, Peter. Culturas da diferença: sequelas das políticas coloniais portuguesas e britânicas na África Austral. Afro-Ásia, Bahia.n 29/30, p. 271-316. 2003.

GASA, E. D. John L. Dube, his Ilanga lase Natal and The Natal African Administration, 1903-1910. Tese de Doutorado, University of Zululand, Pietermaritzburg, 1999.

GROSSMAN, Jonathan. Violência e silêncio: Reescrevendo o futuro. História Oral. Revista da Associação Brasileira de História Oral, 3, 2000.

GUIMARÃES, Antonio Sérgio Alfredo. Combatendo o racismo: Brasil, África do Sul e Estados Unidos. Revista Brasileira de Ciências Sociais. Fev. 1999, v. 14, n. 39, p. 103-115.

HALBWACHS, Maurice. A memória coletiva. São Paulo: Centauro, 2006.

HARRIS, V.The Archival Sliver: Power, Memory, and Archives in South Africa. Archival Science, 2: 63-86, 2002.

HERNANDEZ, L. L. Movimentos de resistência na África. Revista de História, 141, 141149, 1999.

HUGHES, H. Doubly Elite: Exploring the Life of John Langalibalele Dube. Journal of Southern African Studies, 27/3, 2001. 
First President. A life of John L. Dube, founding president of the ANC. Johannesburg: Jacana, 2011.

HOBSBAWM, E. Introdução: A Invenção das Tradições. In.: HOBSBAWM, E.; RANGER, T. (orgs.). A invenção das tradições. Rio de Janeiro: Paz e Terra, 1997.

IZIBONGO - John Langalibalele Dube. Ohlange Library. ILanga, South Africa, 1974.

JELIN, E. Los trabajos de la memoria. Madrid: Siglo XXI Editores, 2002.

KI-ZERBO, Joseph. Introdução Geral. História geral da África, I. 2. ed. Brasília: UNESCO, 2010.

KOSELLECK, R. Futuro Passado. Rio de Janeiro: Contraponto, 2006.

KOTHE, F. R. O Herói. 2. ed. São Paulo: Ática, 1987.

KUMALO, S.. Pastor and Politician. Essays on the Legacy of JL Dube, the First President of the African National Congress. Pietermaritzburg: UKZN, 2003. (Mimeo) . Meeting the Cowboy Turned Renegade Missionary: William Cullen Wilcox. Studia Historiae Ecclesiasticae, V. 39, Sup. 1, Pretoria, Aug, 2013.

LE GOFF, J. Memória e História. Campinas: Editora UNICAMP, 1992.

MARABLE, M. African Nationalist. The Life of John L. Dube. Tese de Doutorado, University of Maryland, Michigan, 1976.

MARKS, S. Reluctant Rebellion. Disturbances in Natal, 1906-08. Oxford: CP, 1970. . The ambiguities of dependence: John L. Dube of Natal. Journal of Southern African Studies, 1(2), 1975.

. Natal, the Zulu Royal Family and the Ideology of Segregation. Journal of Southern African Studies, v. 4, n. 1, out. 1977.

MAYLAM, Paul. South Africa's racial past: the history and historiography of racism, segregation, and apartheid. Abingdon: Routledge, 2016.

MUDIMBE, V.Y. The Invention of Africa: Gnosis, Philosophy and the Order of Knowledge. Bloomington: Indiana University Press, 1988.

The Idea of Africa. Bloomington: Indiana University Press, 1994.

NORA, Pierre. Entre Memória e História. A problemática dos lugares. Projeto História, São Paulo, n. 10, dez. 1993.

NZAMA, E. V. Imagery and oral formulaic language in the late Rev. John Langalibalele (UMAFUKUZELA) Dube's Izibongo. 1992. Dissertação (Master in Orality Literacy Studies) - Faculty of Arts, Inderdisciplinary Studies Programme, University of Natal, Durban, 1992. OBERLIN-INANDA: The Life and Times of John L. Dube. Direção: Chérif Keita; Vancouver: Villon Films, 2006. 1 DVD (54 min).

POLLAK, M. Memória, esquecimento e silêncio. Estudos Históricos, 1: 3-15, 1989. Memória e Identidade Social. Estudos Históricos, 5(10): 200-212, 1992. 
POSEL, D. The Making of Apartheid, 1948-1961. Oxford: Claredon Press, 1991.

RANGER. A Invenção da Tradição na África Colonial. In.: HOBSBAWM, E.; RANGER, T. (orgs.). A invenção das tradições. Rio de Janeiro: Paz e Terra, 1997.

RENAN, E. Qu'est-ce qu'une nation? (Conférence prenoncée le 11 mars 1882 à la Sorbonne), 1882. Disponível em: http://classiques.uqac.ca/classiques/renan_ernest/ qu_est_ce_une_nation/renan_quest_ce_une_nation.pdf. Acesso em: 10.12.2018.

ROOD, D. Letter. In.: DUBE, J. L. A familiar talk upon my native land and some things found there. [s. e.], 1891.

ROSA RIBEIRO, F. A construção da nação (pós-)colonial: África do Sul e Suriname, 1933-1948. Estudos Afro-asiáticos, v. 24, n. 3, p. 483-512, 2002.

SANTOS, B.; MENESES, M. P. (Orgs.). Epistemologias do Sul. São Paulo: Cortez, 2009.

SIVETYE, Gideon M. Tribute a John Dube by the Rev. Gideon M. Sivetye. Ilanga lase Natal, 23 fev. 1946, p. 15.

SOUTH AFRICA's story maker - Shula Marks. The Jewish Chronicle, 14, July, 2017.

STONE, Judith. Retrato em preto e branco: a história verídica de uma família dividida por problemas raciais. São Paulo: Landscape, 2008.

TABATA, I. B. On the Organisations of the African People. From I. B. Tabata to Nelson Mandela, June, 16, 1948.

THE PRESIDENCY. President Zuma. Pretória. Disponível em: http://www.thepresidency. gov.za/pebble.asp?relid=6043, 2012.

UNIVERSITY hounours Natal native leader. The Mercury, 22 set. 1936a.

UNIVERSITY honours Zulu educationist. The Natal Advertiser, 21 set. 1936b.

VALDÉS, E. D. O Pensamento Africano Sul-Saariano. Conexões e paralelos com o pensamento Latino-Americano e o Asiático. São Paulo: Clacso- EDUCAM, 2008.

VANSINA, J. A tradição oral e sua metodologia. In: KI-ZERBO, J. (Coord.). História Geral da África. V. I. 2a ed. São Paulo: Unesco, 2010.

VERDERY, K. Para onde vão a "nação" e o "nacionalismo" ? In.: BALAKRISHNAN, G. (org.). Um mapa da questão nacional. Rio de Janeiro: Contraponto, 2000.

VILAKAZI, B. The Greatest Black Man of the Missionary Epoch in S. Africa. Ilanga lase Natal, 1946.

WILCOX, W. C.. The Story of John Dube: the Booker Washington of South Africa. Congregational, mar. 1927.

ZAMPARONI, V. D. A África e os estudos africanos no Brasil. Ciência e Cultura. V. 59, n. 2, São Paulo, Apr./June 2007.

Entre Narros \& Mulungos. Colonialismo e paisagem social em Lourenço Marques, c. 1890- c.1940. Tese de Doutorado em História, FFLCH/USP, São Paulo, 1998. 
ZUMA, J. G.. Celebrating. 2012a. Disponível em: http://www.anc.org.za/centenary/ show.php?id=9308.

Address by the President of South Africa, at the 1000 year celebration conference... Durban, 2012b. Disponível em: http://www.info.gov.za/speech/ DynamicAction?pageid $=461 \&$ sid $=27620 \&$ tid $=69127$.

\section{Notas}

1 Deve-se reconhecer que, de certo modo, Ernest Renan (1882), um século antes desses pesquisadores, antecipou algumas de suas questões no ensaio Qu'est-ce qu'une nation?.

2 Utilizar-se-á Apartheid para se referir ao sistema oficial instituído na África do Sul entre 1948 e 1994 e apartheid como similar a separação racial.

${ }^{3}$ As análises comparativas que enfocam Brasil e África do Sul se relacionam e lidam com concepções de história e desenvolvimento diferentes e mesmo opostas, a exemplo de perspectivas que priorizam condicionantes materiais e aquelas que acentuam elementos ideológicos e culturais, como se pode observar, paradigmaticamente, quando se confrontam as interpretações do sociólogo A. S. Guimarães (1999) e do antropólogo P. Fry (2003). No final dos anos 1990, Guimarães argumentava que a "ideologia oficial" brasileira, qual seja, "a ideia integracionista de "democracia racial”" (Ibid., p. 110), servia de obstáculo para combater o racismo no Brasil. Nesse contexto, "a África do Sul poderá nos indicar um modelo de nação multicultural, multiétnica e não-racialista de fundamental importância para a agenda anti-racista no Brasil e nos Estados Unidos". A África do Sul precisaria promover a "reversão das desigualdades raciais acumuladas historicamente pelo colonialismo, pela escravidão, pela segregação e pelo racismo" e "construir uma identidade nacional que não desmereça ou anule as identidades étnicas e que não traga embutida em si o racismo de atitudes e de preferências que está entranhado nas identidades nacionais européias e americanas, do Norte e do Sul". (Ibid., p. 114) De outro lado, ao se propor "comparar e contrastar as presenças coloniais britânicas e portuguesas na África austral (e, brevemente, também no Brasil)" (Ibid., p. 273), P. Fry (2003) lembraria que "enquanto os engenheiros sociais da África do Sul traçaram um caminho explícito de segregação racial e étnica e de celebração das diferenças culturais, seus equivalentes em Moçambique imaginaram uma época em que todos os moçambicanos teriam abandonado seus 'usos e costumes' e seus 'dialetos', a favor da 'civilização' e da língua portuguesas” (Ibid., p. 289). Assim, "enquanto Moçambique [o que se poderia também dizer, naquele contexto, do Brasil] caminha em direção a um interesse e preocupação crescentes com a 'diversidade', a África do Sul caminha, muito experimentalmente, em direção à universalidade que a sua experiência colonial tão sistematicamente rejeitou” (Ibid., p. 315). Fry critica a interpretação de Perry Anderson (Portugal e o Fim do ultracolonialismo) acerca do colonialismo português em Moçambique e a compara ao modo como os sociólogos brasileiros criticavam Gilberto Freyre. "Apontavam, em primeiro lugar, para o abismo que divide o 'mito' da 'realidade', documentando a crassa desigualdade social e a persistência da discriminação racial. Mas, da mesma forma que Anderson, iam além afirmando que o mito da democracia racial disfarça o preconceito racial e a discriminação e dificulta a "consciência racial'" (Ibid., p. 277). Contudo, o problema seria que "ambas as críticas baseiam-se na premissa de que o colonialismo britânico representa a 'normalidade' e, ao fazê-lo, revelam uma tradição de mal disfarçado esnobismo em relação aos portugueses" (Ibid., p. 278). Outro problema é que esse tipo de epistemologia "não leva em consideração o fato de que, dentro de cada uma destas esferas de influência coloniais, os dois princípios [assimilacionismo e segregacionismo] foram invocados de um período a outro e, às vezes, simultaneamente" (Ibid., p. 281). 
4 Izibongo são louvores de poesia oral, comum entre os zulus, entoados em honra de uma pessoa heroificável. Imbongi é quem profere o izibongo (Barros, 2018b).

5 "Langalibale" significa "sol nascente" e era nome de um antigo chefe dos hlubi, grupo que, assim como os qadi, faziam parte do povo lala, de onde se originara a família de Dube. Os lalas, que falavam a língua tekeza, foram derrotados e integrados entre os zulus ao longo do século XIX. Alguns lalas, dentre eles o pai de Dube, pediram proteção aos britânicos. No caso da família Dube, isto teria ocorrido depois que seu avô, que era respeitado entre os zulus, fôra assassinado a mando do rei zulu Dingane - história esta que é narrada por Langalibalele em $A$ familiar talk....

${ }^{6}$ Acesso em 21.1.2018.

7Organizado inicialmente por John William Shepstone (1796-1873), o shepstonism consiste num sistema, desenvolvido especialmente na região de Natal, que funcionou como um modelo de governo indireto e se espalhou para outras partes do império britânico em África. Nesse sistema, os chefes africanos foram inseridos no governo oficial, devendo manter a lei e a ordem e coletar taxas e impostos para o governo. Alguns historiadores afirmam que as raízes da segregação se encotram nesse sistema, uma vez que alguns elementos-chave do Apartheid se identificavam ali, especialmente a segregação política e territorial. Ver, dentre outros, Maylam (2016).

8 Disponível em: http://blog.sa-venues.com/provinces/kwazulu-natal/the-inanda-heritage-route/. Acesso em 12.1.2019.

${ }^{9}$ Acesso em 12.1.2019.

Antonio Evaldo Almeida Barros é professor Doutor do Departamento de História, Programa de Pós-Graduação em Políticas Públicas, UFMA - Univ. Federal do Maranhão - Av. dos Portugueses, 1966, Bacanga, CEP 65080-805, São Luís, Maranhão, Brasil. Departamento de História e Geografia, Programa de Pós-Graduação em História, UEMA - Univ. Estadual do Maranhão - Av. Lourenço Vieira da Silva, n. 1000, Jardim São Cristovão, CEP 65055-310, São Luís, Maranhão, Brasil. 